\title{
An outbreak of Salmonella Newport associated with mung bean sprouts in Germany and the Netherlands, October to November 2011
}

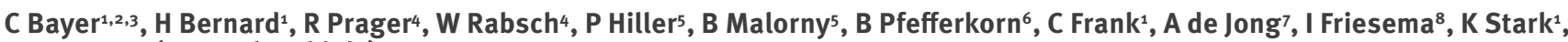

B M Rosner (Rosnerb@rki.de) 1

1. Robert Koch Institute, Department for Infectious Disease Epidemiology, Berlin, Germany

2. Postgraduate Training for Applied Epidemiology (PAE, German Field Epidemiology Training Programme), Robert Koch Institute, Berlin, Germany

3. European Programme for Intervention Epidemiology Training (EPIET), European Centre for Disease Prevention and Control, (ECDC), Stockholm, Sweden

4. Robert Koch Institute, Division of Bacterial Infections and National Reference Centre for Salmonella and other Bacterial Enteric Pathogens, Wernigerode, Germany

5. Federal Institute for Risk Assessment, Department of Biological Safety, Berlin, Germany

6. Federal Office of Consumer Protection and Food Safety, Berlin, Germany

7. Dutch Food and Consumer Product Safety Authority (NVWA), Utrecht, the Netherlands

8. The National Institute for Public Health and the Environment (RIVM), Centre for Infectious Disease Control, Bilthoven, the Netherlands

Bayer C, Bernard H, Prager R, Rabsch W, Hiller P, Malorny B, Pfefferkorn B, Frank C, de Jong A, Friesema I, Stark K, Rosner BM. An outbreak of Salmonella Newport associated with mung bean sprouts in Germany and the Netherlands, October to November 2011. Euro Surveill. 2014;19(1):pii=20665. Available online: http://www. eurosurveillance.org/ViewArticle.aspx?Articleld $=20665$

The largest Salmonella enterica serovar Newport outbreak $(n=106)$ ever reported in Germany occurred in October and November 2011. Twenty associated cases were reported in the Netherlands. The outbreak investigation included an analytical epidemiological study, molecular typing of human and food isolates and food traceback investigations. Unspecified Salmonella had been detected in samples of mung bean sprouts at a sprout producer (producer A) in the Netherlands and mung bean sprouts contaminated with $S$. Newport had been found during routine sampling at a sprout distributor in Germany. Therefore, we tested the hypothesis of sprouts being the infection vehicle. In a case-control study, we compared 50 notified adult S. Newport cases with 45 Salmonella enterica serovar Enteritidis cases regarding their food consumption in the three days before illness. In multivariable logistic regression analysis, only sprout consumption was significantly associated with $S$. Newport infection (odds ratio: 18.4; 95\% confidence interval: 2.2-150.2). Molecular typing patterns of human isolates were indistinguishable from a mung bean sprouts isolate. Traceback of sprouts led to distributors and producer $A$ in the Netherlands. Since sprouts are frequently contaminated with microorganisms, consumers need to be aware that consumption of raw or insufficiently cooked sprouts may pose a health risk.

\section{Introduction}

Foodborne Salmonella infections are a significant public health problem in many countries, including Germany and the Netherlands. Salmonella enterica serovar Newport has been an uncommon cause of acute gastroenteritis in Germany with a mean of 113 notified cases per year in the time period 2001 to 2010. In 2010 , a total of 25,310 cases of Salmonella infections were notified, of which only $83(0.3 \%)$ were caused by S. Newport [1]. In comparison, $22(1.5 \%)$ of the 1,466 reported Salmonella infections were $S$. Newport infections in the Netherlands in 2010. Twenty-four outbreaks of $S$. Newport were reported in Germany from 2001 to 2010. The number of respective outbreak-associated cases only ranged from two to nine. Notification data did not include information on possible sources of these outbreaks. S. Newport outbreaks in other European countries and the United States (US) were linked to the consumption of various food items such as ground beef [2], horse meat [3], cheese [4], tomatoes [5], lettuce $[6,7]$, ready-to-eat salad vegetables [8] and alfalfa sprouts [9]. Mung bean sprouts were associated with outbreaks of Salmonella serovars other than Newport [10-13], but to our knowledge, mung bean sprouts have not been described as the infection vehicle in a $S$. Newport outbreak to date.

In Germany, in November 2011, the National Reference Centre for Salmonella and other bacterial enteric pathogens (NRC) at the Robert Koch Institute (RKI) observed an increase of $S$. Newport isolates originating from patients who had developed gastroenteric symptoms during a stay at a rehabilitation clinic in northern Germany, which indicated an outbreak situation. An increase of $S$. Newport isolates was also reported by the Institute of Hygiene and the Environment in Hamburg, a large diagnostic laboratory. Furthermore, analysis of 
data from the national surveillance database of notifiable infectious diseases at the RKI revealed a substantial increase of notified $S$. Newport cases from an annual average of two or three cases per week in 2001 to 2010, to eight in week 43 and 39 in week 44 of 2011. By 21 November 2011, S. Newport infections had been recorded in 15 of the 16 federal states in Germany since the end of October 2011.

In the Dutch laboratory surveillance network for gastroenteric pathogens, 16 regional public health laboratories send Salmonella isolates from patients to the National Institute for Public Health and the Environment (RIVM) for confirmation and further typing [14]. This surveillance network was established in 1987, and has been estimated to cover approximately $64 \%$ of the population. An unusual increase of $S$. Newport isolates in October and November 2011 was noticed and communicated on 21 November 2011 via the Epidemic Intelligence Information System (EPIS), located at the European Centre for Disease Prevention and Control (ECDC). In addition, Germany and the Netherlands informed other European countries through the European Early Warning and Response System (EWRS) on 21 and 22 November 2011, respectively.

Mung bean sprouts were suspected as the vehicle in the outbreak because two lots of mung bean sprouts contaminated with an unspecified serovar of Salmonella had been found at sprout producer $A$ in the Netherlands, sampled during the company's own testing of production batches on 18 and 21 October 2011, and S. Newport had been detected in mung bean sprouts taken during routine sampling at a sprout distributor in northern Germany on 19 October 2011. The mung bean sprouts originated from one of the contaminated lots produced in the Netherlands. Sprouts had been delivered to the distributor from producer A on 18 October 2011. These findings were notified to European food safety and public health authorities through the Rapid Alert System for Food and Feed (RASFF) of the European Commission on 17 November and, as a first follow-up, on 8 December 2011, roughly coinciding with the beginning of the outbreak investigation.

Here we describe the outbreak investigation launched to identify the source of the outbreak, including an epidemiological study, microbiological analyses and traceback investigations.

\section{Methods}

On 21 November 2011, the RKI, the national public health authority in Germany, was invited by state health authorities in one of the affected federal states to support the outbreak investigation. The outbreak investigation was coordinated by RKI and the Federal Institute for Risk Assessment (BfR) in close collaboration with the local and state human health and food safety authorities as well as the Federal Office of Consumer Protection and Food Safety (BVL). Information on the respective outbreak investigations was exchanged between RKI and RIVM. Traceback investigations were conducted by local and state food safety authorities and coordinated by the BfR on the federal level. The BVL cooperated with the corresponding Dutch Food Safety Authority (NVWA) to investigate supply chains in the Netherlands.

In the Netherlands, the RIVM requested the regional public health services to contact the cases within their region. Simultaneously, the NVWA was informed that an outbreak investigation was started. The RIVM and the NVWA exchanged information on the progress of the investigation on a regular basis.

\section{Case definition of outbreak cases}

In Germany, a case was defined as a laboratoryconfirmed S. Newport infection notified to the public health authorities with at least one symptom of acute gastroenteritis (diarrhoea or stomach pain or vomiting or fever) and onset of symptoms between 20 October and 8 November 2011. Illnesses were not considered as outbreak-related if case patients reported travelling outside of Germany in the three days before onset of symptoms, or if molecular subtyping of the $S$. Newport isolate by pulsed-field gel electrophoresis (PFGE) revealed a pattern different from the outbreak strain. If the date of onset of symptoms was not available from notification data, it was estimated by subtracting from the reported notification date the average time interval between date of disease onset and date of notification available from notified cases with reported date of disease onset (11 days).

In the Netherlands, a case was defined as a $S$. Newport infection laboratory-confirmed at the RIVM in October or November 2011. Cases were excluded as outbreak cases, if PFGE revealed a pattern different from the outbreak strain and/or the case had been abroad in the seven days before disease onset.

\section{Case-control study in Germany}

We conducted a case-control study to test the hypothesis that consumption of mung bean sprouts was associated with illness. S. Newport case patients 18 years or older were compared with a control group of $S$. Enteritidis patients regarding frequency of exposure to suspected risk factors (case-case design). Controls were defined as laboratory-confirmed $S$. Enteritidis infections in adults (18 years or older) notified to the public health authorities with at least one symptom of acute gastroenteritis and onset of symptoms between 14 November and 11 December 2011. Controls were excluded if they reported travelling outside of Germany in the three days before onset of symptoms. If the date of onset of symptoms was missing from notification data, it was estimated based on S. Enteritidis controls with available data as described above for case patients (average time interval between disease onset and notification: 10 days). 
Cases and controls were frequency-matched by age groups (18-31 years, 32-48 years, 49-88 years). All case patients and controls were recruited by local health authorities in their county of residence. Informed consent from participants was obtained through local health authorities before the interview. Staff from RKI and from state health authorities (Bavaria and Baden-Wuerttemberg) conducted the interviews by telephone using a standardised questionnaire. Questions referred to the three days before disease onset and were focused on the consumption of sprouts and food items that often contain mung bean sprouts, such as wok dishes, Asian rolls, and salads. Furthermore, the questionnaire queried about eating in restaurants offering Asian food or in other restaurants, about consumption of food items that were already known to be a potential source for Salmonella infections, such as raw pork, about symptoms, duration of illness, and basic demographics.

\section{Case patient interviews in the Netherlands}

Fifteen of 20 case patients were interviewed using a standardised questionnaire. This trawling questionnaire covered consumption of different meats, fish, dairy products, vegetables and fruits, snacks, establishments where food was purchased and contact with animals, in the seven days before onset of illness. Furthermore, information about the symptoms, onset of illness and hospitalisation was obtained. The Dutch case patients were not included in the case-control study.

\section{Statistical analyses}

Univariate and multivariable logistic regression analyses of data acquired for the case-control study were performed using Stata version 12 (Stata Corporation, College Station, US). Exposure-specific odds ratios (OR) and 95\% confidence intervals (CI) were calculated. All exposure variables with a $p$ value 0.1 in univariate analysis were included in the multivariable analysis. Regression models were built using forward elimination of variables with a cut-off $p$ value of 0.05 , and adjusted for age group and sex. Rank sum or t-tests were used for comparison of continuous variables.

As the investigation of the large outbreak of Shiga toxin-producing Escherichia coli (STEC) $0_{104}: \mathrm{H}_{4}$ in Germany in 2011 showed that consumption of sprouts is difficult to remember [15], a variable was created to describe 'probable sprout consumption'. This variable was defined as affirmed sprout consumption or having eaten in an Asian restaurant or having stayed in the rehabilitation clinic in northern Germany, where sprouts had been served at the salad bar.

In the Netherlands, the questionnaires were entered in Questback (Questback, Oslo, Norway). Frequency tables were generated using the export function. A variable for 'probable sprout consumption' was created by combining variables for reported affirmed and possible sprout consumption and reported meals that typically or possibly contained sprouts, for example Asian meals.

\section{Microbiological methods}

In Germany, for human isolates of $S$. Newport cases, the NRC performed PFGE using Xbal restriction enzyme following the PulseNet CDC-Protocol [16]. For comparison of PFGE patterns, additional $S$. Newport isolates were provided to the NRC by the Hamburg Institute for Hygiene and the Environment (human and animal isolates), by the National Reference Laboratory for Salmonella at the BfR (NRL-Salm) (isolates from turkey and mung bean sprouts) and by the Technical University of Denmark, Copenhagen (isolates from turkey meat originating from Germany). In addition, the NRL-Salm analysed $33 \mathrm{~S}$. Newport isolates that had been isolated between 2009 and 2011 from food items (turkey and chicken), reptiles and other animal and environmental sources. Furthermore, human isolates, including the outbreak strain, were provided to the NRL by the NRC for comparison. The NRL-Salm performed Xbal-PFGE and an in-house multiple-locus variable number tandem repeat analysis (MLVA) method for Salmonella enterica isolates comprising the determination of eight repetitive loci. The MLVA method was performed by capillary electrophoresis according to Malorny et al. [17] using the following loci: STTR9, STTR5, STTR3, STTR11 [18,19] Salo2, Salo6, Sal2o [20] and SE-7 [21]. Antimicrobial susceptibility of strains was tested against 14 antimicrobial drugs or drug combinations by determining the minimum inhibitory concentration (MIC) using the Clinical and Laboratory Standards Institute's broth micro dilution method [22] in combination with the semi-automatic Sensititre system (TREK Diagnostic Systems, Cleveland, US). Cut-off values $(\mathrm{mg} / \mathrm{L})$ to determine susceptibility to 10 antimicrobials were applied as described in the Commission Decision on a harmonised monitoring of antimicrobial resistance in poultry and pigs [23], namely cefotaxime (FOT, >0.5), nalidixic acid (NAL, >16), ciprofloxacin (CIP, >0.06), ampicillin (AMP, >4), tetracycline (TET, >8), chloramphenicol (CHL, >16), gentamicin (GEN, >2), streptomycin (STR, 132), trimethoprim (TMP, 12) and sulfamethoxazole (SMX, 2256). Cut-off values for the remaining four antimicrobials were adopted from the European Committee on Antimicrobial Susceptibility Testing [24] namely colistin (COL, >2), florfenicol (FFN, >16), kanamycin (KAN, >32) and ceftazidime (TAZ, >2).

In the Netherlands, human isolates from $S$. Newport cases were compared using PFGE as described above.

\section{Traceback and environmental investigations}

Starting from the rehabilitation clinic and from Asian restaurants where $S$. Newport cases reported to have eaten in the three days before disease onset, mung bean sprouts were traced back. Traceback investigations were only initiated if the information provided by case patients regarding the restaurant and the date they had eaten there was considered sufficiently specific. 
Notified Salmonella Newport cases by date of disease onset, Germany and the Netherlands, 1 October-15 November 2011 $(n=133)$

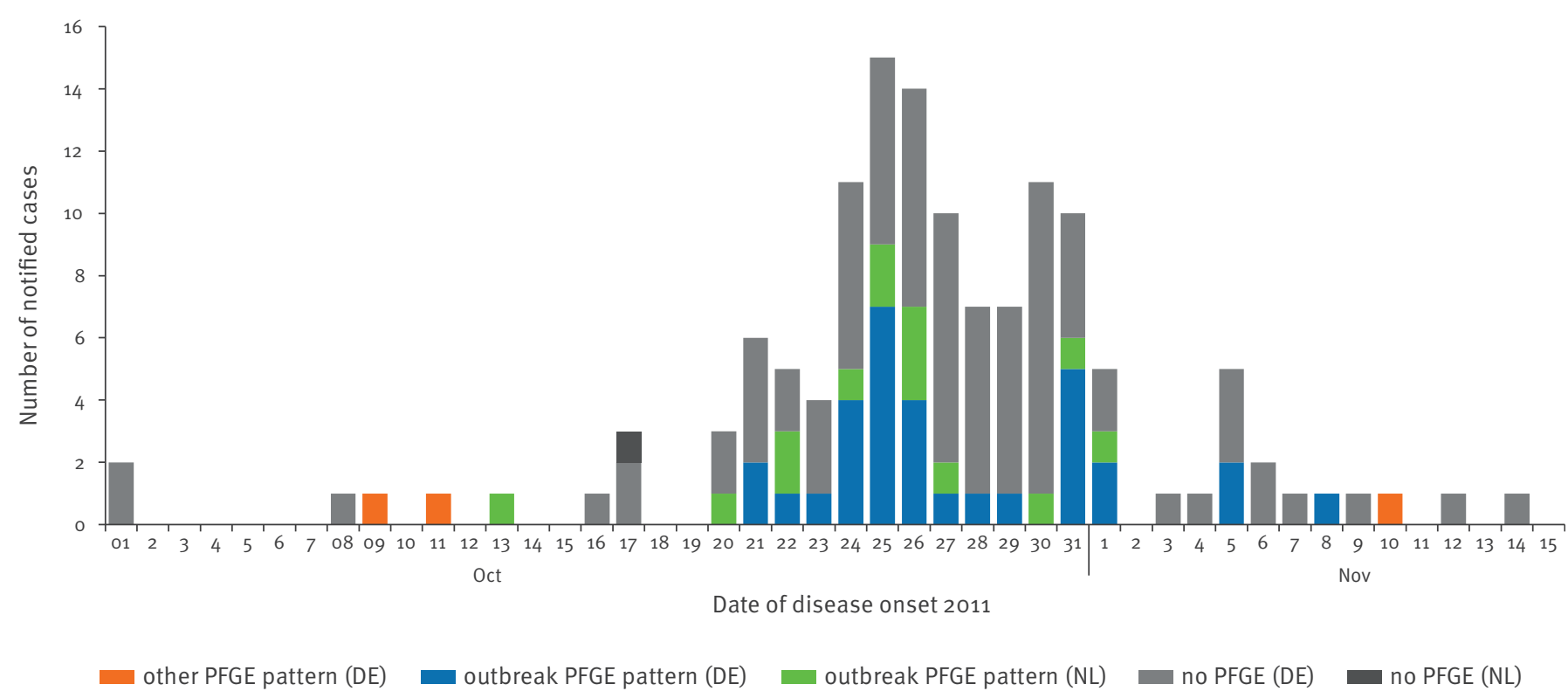

106 notified S. Newport cases were associated with the $S$. Newport outbreak in Germany (disease onset from 20 October- 08 November 2011 , outbreak period in Germany). Twenty $S$. Newport cases were notified in the Netherlands, of whom 15 with disease onset from 13 October to 1 November 2011 (outbreak period in the Netherlands) were interviewed and are included in the epidemic curve.

Local food safety authorities also collected information in these restaurants on how mung bean sprouts were prepared and served. In the rehabilitation clinic in northern Germany, samples from leftover food items and stool samples from kitchen personnel were taken.

In the Netherlands, sprouts served in a hospital where two cases were hospitalised during the incubation period were traced back.

\section{Results}

\section{Descriptive epidemiology}

In total, the outbreak in Germany comprised 106 cases (Figure 1). Median age was 38 years (range: 0-91 years). Fifty-two per cent of cases were female. Hospitalisation due to $S$. Newport infection was reported for $28 \%$ of the cases. No deaths were reported.

In the Netherlands, a total of 20 outbreak-related $S$. Newport cases were reported. The onset of illness, known for 15 of the Dutch outbreak-related case patients, was between 13 October and 1 November 2011 (Figure 1). Median age was 37 years (range: 10-89 years), 15 cases were female. Two cases were already hospitalised when developing gastrointestinal symptoms, and for three cases no information on hospitalisation was available. Seven of the remaining 15 cases were hospitalised. Four of 15 interviewed case patients reported having eaten or possibly having eaten sprouts in the seven days before disease onset, and another nine case patients reported having eaten meals in which sprouts are typically used or could be used. For the remaining two case patients, no link to possible sprout consumption was found.

\section{Case-control study in Germany}

Fifty cases and 45 controls were included in the casecontrol study. The remaining 56 cases could not be contacted, were not willing to be interviewed, or did not meet the inclusion criteria for study participation because they were younger than 18 years or had travelled in the three days before disease onset. S. Newport case patients participating in the case-control study differed from non-participating adult case patients $(n=47)$ with respect to age (median age 44 years versus 34 years) and sex ( $48 \%$ versus $51 \%$ female). More than $60 \%$ of contacted $S$. Enteritidis cases agreed to participate in our study as control group, and contact data of $56 \%$ of these controls were forwarded to the RKI within two working days after the request was made to the local health authorities. The median time interval between disease onset and interview was 51 days (interquartile range (IQR): 48-53 days) for S. Newport case patients and 35 days (IQR: 24-42 days) for $S$. Enteritidis controls. Case patients were slightly younger than controls (median age: 44 years versus 50 years). Twenty-four of 50 case patients and 22 of 45 control patients were female. The most frequently reported symptoms in $S$. Newport case patients were 
Risk factors for infection: results of univariate and multivariable logistic regression analysis of case-control study, Salmonella Newport outbreak, Germany, 20 October-8 November 2011 ( $\mathrm{n}=50$ cases, 45 controls)

\begin{tabular}{|c|c|c|c|c|}
\hline \multirow[b]{2}{*}{$\begin{array}{l}\text { Exposure } \\
\text { (Food items/restaurant visit) }\end{array}$} & Cases & Controls & \multirow[b]{2}{*}{$\begin{array}{l}\text { Odds Ratio } \\
{[95 \% \mathrm{Cl}]}\end{array}$} & \multirow[b]{2}{*}{$p$ value $^{a}$} \\
\hline & Exposed/total (\%) & Exposed/total (\%) & & \\
\hline \multicolumn{5}{|l|}{ Univariate } \\
\hline Probable sprout consumption & $21 / 50(42)$ & $1 / 45(2)$ & $31.9\left[4 \cdot 5^{-1,346]}\right.$ & $<0.001$ \\
\hline Eating out (Asian restaurant) & $13 / 47(28)$ & $0 / 45(0)$ & $23.1[3.6-\infty]^{\mathrm{b}}$ & $<0.001$ \\
\hline Affirmed sprout consumption & $14 / 43(33)$ & $1 / 45(2)$ & $21.2[2.9-918]$ & $<0.001$ \\
\hline Asian vegetables & $8 / 47(17)$ & $0 / 43(0)$ & $11.7[1.7-\infty]^{\mathrm{b}}$ & 0.008 \\
\hline Turkey & $16 / 41(39)$ & $5 / 39(12)$ & $4.4[1.3-17.0]$ & 0.008 \\
\hline Eating out (non-Asian restaurant) & $34 / 49$ (69) & $19 / 45(42)$ & $3.1[1.2-7.9]$ & 0.008 \\
\hline Salad & $12 / 45(27)$ & $14 / 37(38)$ & $2.7[1.0-7.1]$ & 0.036 \\
\hline Ready-made sandwiches & $8 / 50(16)$ & $9 / 45(20)$ & $2.3[0.9-5.7]$ & 0.049 \\
\hline \multicolumn{5}{|l|}{ Multivariable model $1^{c}$} \\
\hline Probable sprout consumption & & & $34.6[4.3-279]$ & 0.001 \\
\hline \multicolumn{5}{|l|}{ Multivariable model $2^{c}$} \\
\hline Affirmed sprout consumption & & & $18.4[2.2-150]$ & 0.007 \\
\hline
\end{tabular}

$\mathrm{Cl}$ : confidence interval.

Exposure variables with a p value $<0.1$ in univariate analysis were included in the multivariable analysis.

b Exact logistic regression.

Controlled for age group and sex.

diarrhoea (50/50) and abdominal pain (34/50). Median duration of symptoms was six days (range: 1-28 days). Ten case patients and 15 controls reported hospitalisation associated with their Salmonella infection. Interviews with case-patients and controls showed that 14 of 43 case-patients that provided information on sprout consumption and only one person out of the 45 controls recalled having eaten sprouts in the three days before onset of symptoms. Of the 14 case-patients who recalled sprout consumption, eight could not name the kind of sprouts they had eaten, one named mung bean sprouts, four named soybean sprouts, and one named other sprouts. Ten case-patients remembered that the consumed sprouts had been long and white, the kind of sprouts typically served in Asian restaurants, and eight recalled that the sprouts had been raw $(n=5)$ or only briefly heated $(n=3)$. In univariate analysis, probable sprout consumption was associated strongest with S. Newport infection (Table). Statistically significant association with $S$. Newport disease was also found for eating in Asian restaurants, affirmed sprout consumption, consumption of Asian vegetables, consumption of turkey, eating in (non-Asian) restaurants, consumption of salad and ready-to-eat sandwiches (Table). In multivariable analysis, controlled for age group and sex, only probable sprout consumption and affirmed sprout consumption remained significantly associated with S. Newport infection (Table).

\section{Microbiology}

From the $106 \mathrm{~S}$. Newport case patients attributed to the outbreak in Germany, 32 isolates were available for PFGE analysis at the NRC. All human isolates, of which 14 originated from patients included in the case-control study, showed an identical PFGE pattern. The PFGE pattern was indistinguishable from the pattern of the mung bean sprout isolate, which originated from a sample taken in October 2011 during routine food sampling at a distributor in northern Germany (Figure 2). This PFGE pattern had not been registered before in the NRC database which includes 230 S. Newport strains analysed in the years 2000 to 2011. An additional 33 S. Newport isolates from food items, animals, and environmental sources were analysed at the NRL-Salm at the BfR. With the exception of the mung bean sprout isolate, all of those showed PFGE and MLVA patterns that were different from the pattern of the outbreak strain. Outbreak isolates were susceptible to all 14 of the tested antimicrobial agents. Seventeen of the isolates that differed in PFGE and MLVA pattern from the outbreak strain were resistant to at least one antimicrobial agent. 
Pulsed-field gel electrophoresis of XbaI-digested genomic DNA from the Salmonella Newport outbreak strain,

Germany, 20 October- 8 November 2011
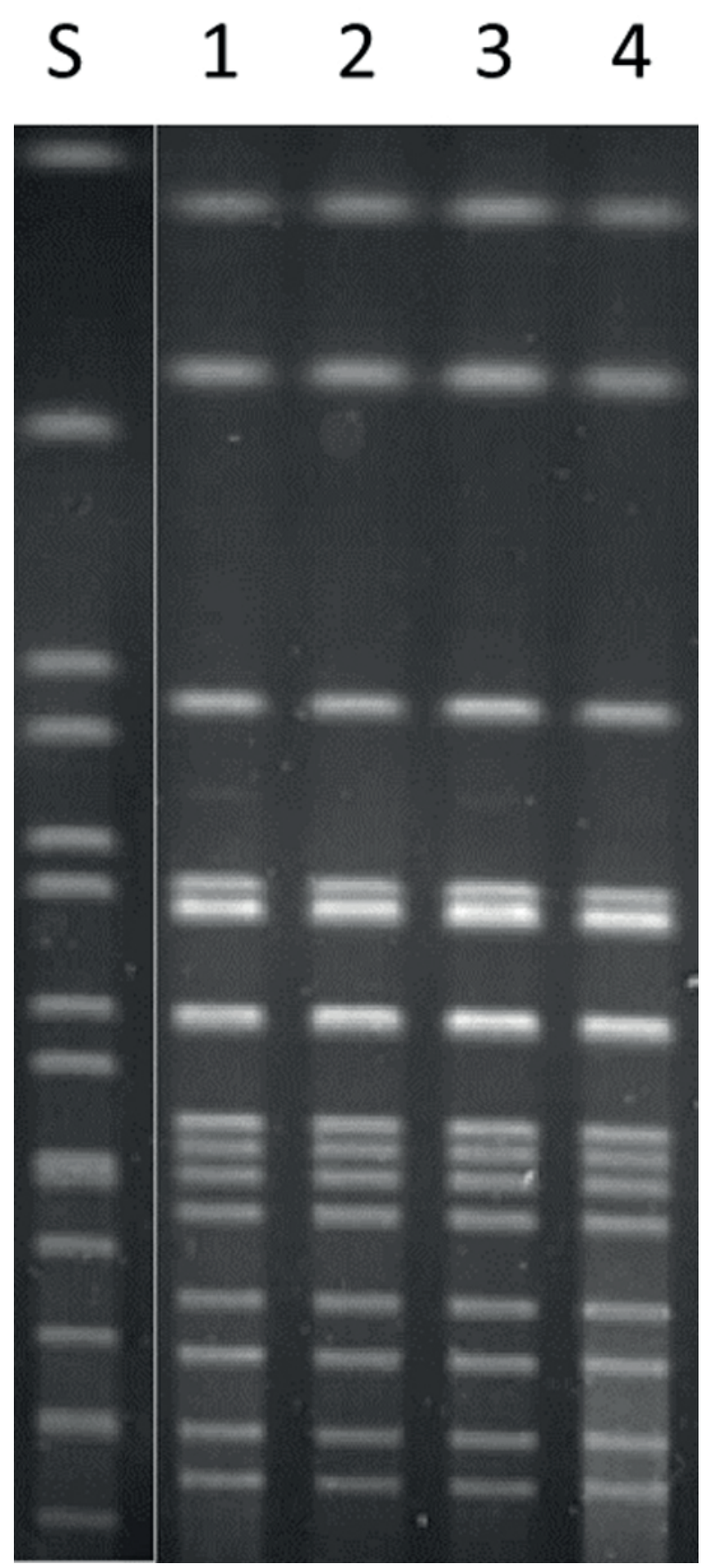

Lanes 1-3: human isolates from case patients; lane 4: mung bean sprout isolate; lane S: the PulseNet universal size standard Salmonella enterica serovar Braenderup H9812 strain.
In the Netherlands, 18 of the 20 case patients had an identical PFGE pattern and two were without PFGE confirmation. The PFGE pattern was indistinguishable from the PFGE pattern of isolates from the German case patients and the mung bean sprout isolate.

\section{Traceback and environmental investigations}

Sprouts served in the rehabilitation clinic in Northern Germany could be traced back via a distributor to producer $A$ in the Netherlands. Six Asian restaurants where cases had eaten before falling ill had received mung bean sprouts from sprout producer $A$, some of them via several distributors.

The restaurants under investigation reported that sprout preparation varied from briefly heated (addition of sprouts to the dish shortly before serving it) to well cooked (sprouts cooked with the dish). At the rehabilitation clinic, sprouts had been served uncooked at the salad bar. All stool samples taken from kitchen staff and all retained food samples collected in the clinic tested negative for $S$. Newport. However, samples of the mung bean sprouts that had been served at the clinic's salad bar were not available for testing.

In the Netherlands, sprouts served in the affected hospital were traced back via several distributors to producer $\mathrm{A}$.

\section{Discussion \\ We describe the largest $S$. Newport outbreak in Germany reported to date, involving 106 cases, with an additional 20 cases in the Netherlands. We conclude that a single strain of $S$. Newport caused illness in the German and Dutch cases. Combined efforts of epide- miologists, microbiologists and food safety authori- ties identified contaminated mung bean sprouts as the source of the outbreak.}

The case-control study revealed a strong and significant association between sprout consumption and $S$. Newport infection. Patients able to recall the type of sprouts they had eaten named mung bean or soybean sprouts, which are often confused with mung bean sprouts. Some patients were unable to name the type of sprouts, but their description of the consumed sprouts was consistent with mung bean sprouts. Case patients infected with $S$. Newport showing the outbreak PFGE pattern in Germany and the Netherlands fell ill between 13 October and 8 November 2011. The epidemic curve showed a distinct peak from 21 October to 5 November 2011, which suggested an infection vehicle that was in circulation only for a limited time period, consistent with a contaminated food item with a short shelf-life, such as mung bean sprouts.

Self-reported sprout consumption could explain only one third of the cases (14/43). This is in line with other epidemiological investigations where sprouts have been identified as vehicle of infection, e.g. a 
multinational S. Newport outbreak in the US and Canada in 1995, and the large STEC $0_{104}: \mathrm{H}_{4}$ outbreak in Germany in $2011[9,15]$. In these outbreaks, sprout consumption was remembered by only $41 \%$ and $25 \%$ of interviewed cases, respectively $[9,15]$. However, when a methodology was used in the latter outbreak that relied on recipe-based data rather than on patient memory, it was confirmed that all cases had consumed sprouts [15]. Sprouts are often used as garnish or side dishes, or are served mixed with other food items in dishes such as Asian rolls, which makes them difficult to remember by patients and renders them classical 'stealth' vehicles. The long time lag between exposure period and the interview may be another reason why the proportion of cases who recalled sprout consumption was small. Furthermore, case patients may have been infected by other food items that were cross-contaminated via kitchen staff and tools. The proportion of case patients who remembered sprout consumption was higher among those with $S$. Newport isolates showing the outbreak PFGE pattern $(10 / 14 ; 71 \%)$ than among all case patients (14/43). Since molecular typing could be performed only in about one third of the cases, it cannot be excluded that some of the 106 cases were misclassified as belonging to the outbreak. However, the background occurrence of $S$. Newport infections in the general population is low, and we therefore assume that the number of cases falsely attributed to the outbreak was small.

Comparative molecular typing was instrumental in detecting the outbreak vehicle, as the PFGE pattern of 32 human isolates was indistinguishable from the mung bean sprouts isolate. In addition, food traceback investigations were crucial, because sprouts served at locations where cases had eaten could be linked to sprout producer A where Salmonella-contaminated sprouts had been detected. It can only be speculated whether the seeds used by the producer were contaminated, as has been described for other outbreaks associated with sprouts $[12,25]$.

In our case-control study we selected notified cases with $S$. Enteritidis infection as control group for various reasons: (i) they could be contacted in a timely manner and recruited more easily than healthy individuals because contact information was available at the local health authorities; (ii) we assumed that symptomatic individuals would be more willing to participate in an epidemiological study and would remember food consumption better than healthy individuals; (iii) we assumed that $S$. Newport case patients and $S$. Enteritidis controls would remember food items consumed before disease onset equally well since we aimed at conducting the interviews within a similar time period after disease onset in cases and controls; (iv) we assumed that consumption habits of $S$. Enteritidis controls would not differ from those of the source population for S. Newport cases; (v) S. Enteritidis infection is not typically associated with consumption of mung bean sprouts. We do not assume that our study was biased by this methodological approach, which has been described before [26-29], because we have no reason to believe that sprout consumption habits of $S$. Enteritidis patients would be different from those of the general population. Eggs and chicken meat are typical transmission vehicles of $S$. Enteritidis infections, although occasionally mung bean sprouts have been associated with $S$. Enteritidis infections in outbreaks [12].

Contaminated fresh produce has increasingly been recognised as an important source of foodborne outbreaks [30]. The outbreak caused by mung bean sprouts described here occurred shortly after the 2011 STEC 0104:H4 outbreak in Germany caused by fenugreek sprouts. Neither in Germany nor in the Netherlands was a consumer warning against the consumption of the implicated lots of mung bean sprouts released. At the time when sprouts were suspected as the outbreak vehicle and when the outbreak investigation began, the shelf life of the implicated mung bean sprouts lots (26 October 2011) had already expired by about a month, and it was assumed that sprouts of these lots had already been consumed or discarded. Also, after the second lot of sprouts had tested positive for Salmonella at producer A (sample from 21 October 2011), the incriminated seed lots had been blocked at that site.

Only at one site of exposure (the clinic in northern Germany) had uncooked mung bean sprouts been served. Although restaurants stated that they had at least briefly cooked the sprouts, temperature and/or duration of cooking of the sprouts were obviously not adequate to kill $S$. Newport bacteria. Our findings demonstrate once again that consumption of raw or briefly cooked sprouts is associated with a considerable risk of foodborne illness. Since sprouts are known to be frequently contaminated with microorganisms [31,32], consumer advice clearly stating the health risks associated with sprout consumption and the safe preparation of sprouts before consumption is essential for prevention of illness in the general population. In addition, more frequent routine microbiological examination of sprouts and seeds may help to increase consumer safety and avoid distribution of contaminated lots.

General consumer advice on the consumption of sprouts was already published in June 2010 and updated in May 2011 by the BfR. Thorough washing of sprouts before consumption is recommended to reduce the risk of infection [31]. Persons who may be vulnerable because their immune system is not fully developed or weakened (children, pregnant women, elderly and immunocompromised) should refrain from consuming raw or lightly cooked sprouts [31-33], and insufficiently heated sprouts should not be served to them in institutional settings [34]. 


\section{Acknowledgments}

The authors thank the local health authorities for recruiting participants for the case-control study in Germany and for interviewing patients with $S$. Newport infections in the Netherlands, the study participants, and the state health authorities for their support. We would also like to thank the local and state food safety authorities for their support of the traceback investigations. The authors are grateful to Dr Andrea Graff, Institute of Hygiene and the Environment, Hamburg, Germany, and Dr Gitte Sørensen, Technical University of Denmark, Copenhagen, Denmark, for providing Salmonella Newport isolates. The authors thank $\mathrm{Dr}$ Katharina Alpers (PAE coordinator, RKI) for her valuable comments on the manuscript.

\section{Conflict of interest}

None declared.

\section{${ }^{*}$ Erratum:}

References 27 to 34 were left out in the originally published reference list. They were added on 13 January 2014. We apologise for this mistake.

\section{References $^{\star}$}

1. Robert Koch-Institut. Infektionsepidemiologisches Jahrbuch für 2010. [Annual epidemiological report on notifiable infectious diseases in Germany 2010]. Berlin: Robert Koch-Institute; 2011. German.

2. Schneider JL, White PL, Weiss J, Norton D, Lidgard J, Gould LH, et al. Multistate outbreak of multidrug-resistant Salmonella newport infections associated with ground beef, October to December 2007. J Food Prot. 2011;74(8):1315-9. http://dx.doi.org/10.4315/0362-028X.JFP-11-046 PMid:21819658

3. Espie E, De Valk H, Vaillant V, Quelquejeu N, Le Querrec F, Weill FX. An outbreak of multidrug-resistant Salmonella enterica serotype Newport infections linked to the consumption of imported horse meat in France. Epidemiol Infect. 2005;133(2):373-6.

http://dx.doi.org/10.1017/So950268804003449 PMid:15816165

4. Centers for Disease Control and Prevention (CDC). Outbreak of multidrug-resistant Salmonella enterica serotype Newport infections associated with consumption of unpasteurized Mexican-style aged cheese--Illinois, March 2006-April 2007. MMWR Morb Mortal Wkly Rep. 2008;57(16):432-5. PMid:18437118

5. Greene SK, Daly ER, Talbot EA, Demma LJ, Holzbauer S, Patel NJ, et al. Recurrent multistate outbreak of Salmonella Newport associated with tomatoes from contaminated fields, 2005. Epidemiol Infect. 2008;136(2):157-65. http://dx.doi.org/10.1017/S095026880700859X PMid:17475091 PMCid:PMC 2870807

6. Lienemann T, Niskanen T, Guedes S, Siitonen A, Kuusi M, Rimhanen-Finne R. Iceberg lettuce as suggested source of a nationwide outbreak caused by two Salmonella serotypes, Newport and Reading, in Finland in 2008. J Food Prot. 2011;74(6):1035-40.

http://dx.doi.org/10.4315/0362-028X.JFP-10-455 PMid:21669088

7. Irvine WN, Gillespie IA, Smyth FB, Rooney PJ, McClenaghan A, Devine MJ, et al. Investigation of an outbreak of Salmonella enterica serovar Newport infection. Epidemiol Infect. 2009;137(10):1449-56. http://dx.doi.org/10.1017/S0950268809002416 PMid:19296871

8. Ward LR, Maguire C, Hampton MD, de Pinna E, Smith HR, Little CL, et al. Collaborative investigation of an outbreak of Salmonella enterica serotype Newport in England and Wales in 2001 associated with ready-to-eat salad vegetables. Commun Dis Public Health. 2002;5(4):301-4. PMid:12564245

9. Van Beneden CA, Keene WE, Strang RA, Werker DH, King AS, Mahon B, et al. Multinational outbreak of Salmonella enterica serotype Newport infections due to contaminated alfalfa sprouts. JAMA. 1999;281(2):158-62.

http://dx.doi.org/10.1001/jama.281.2.158

PMid:9917119

10. Honish L, Nguyen Q. Outbreak of Salmonella enteritidis phage type 913 gastroenteritis associated with mung bean sprouts-Edmonton, 2001. Can Commun Dis Rep. 2001;27(18):151-6. PMid:11582621

11. van Duynhoven YT, Widdowson MA, de Jager CM,

Fernandes T, Neppelenbroek S, van den Brandhof W, et al. Salmonella enterica serotype Enteritidis phage type $4 \mathrm{~b}$ outbreak associated with bean sprouts. Emerg Infect Dis. 2002;8(4):440-3.

http://dx.doi.org/10.3201/eido804.010375 PMCid:PMC 2730239

12. Mohle-Boetani JC, Farrar J, Bradley P, Barak JD, Miller M, Mandrell R, et al. Salmonella infections associated with mung bean sprouts: epidemiological and environmental investigations. Epidemiol Infect. 2009;137(3):357-66. http://dx.doi.org/10.1017/So950268808000411 PMid:18294429

13. Cleary P, Browning L, Coia J, Cowden J, Fox A, Kearney J, et al. A foodborne outbreak of Salmonella Bareilly in the United Kingdom, 2010. Euro Surveill. 2010;15(48):pii=19732. Available from: http://www.eurosurveillance.org/ViewArticle. aspx?Articleld $=19732$

14. van Pelt W, de Wit MA, Wannet WJ, Ligtvoet EJ, Widdowson MA, van Duynhoven YT. Laboratory surveillance of bacterial gastroenteric pathogens in The Netherlands, 1991-2001. Epidemiol Infect. 2003;130(3):431-41.

PMid:12825727

15. Buchholz U, Bernard H, Werber D, Bohmer MM, Remschmidt C, Wilking H, et al. German outbreak of Escherichia coli 0104: $\mathrm{H}_{4}$ associated with sprouts. N Engl J Med. 2011;365(19):1763-70. http://dx.doi.org/10.1056/NEJMoa1106482 PMid:22029753

16. Ribot EM, Fair MA, Gautom R, Cameron DN, Hunter SB, Swaminathan B, et al. Standardization of pulsed-field gel electrophoresis protocols for the subtyping of Escherichia coli 0157:H7, Salmonella, and Shigella for PulseNet. Foodborne Pathog Dis. 2006;3(1):59-67. http://dx.doi.org/10.1089/ fpd.2006.3.59 PMid:16602980

17. Malorny B, Junker E, Helmuth R. Multi-locus variable-number tandem repeat analysis for outbreak studies of Salmonella enterica serotype Enteritidis. BMC Microbiol. 2008;8:84. http://dx.doi.org/10.1186/1471-2180-8-84 PMid:18513386 PMCid:PMC2430564

18. Lindstedt BA, Heir E, Gjernes E, Kapperud G. DNA fingerprinting of Salmonella enterica subsp. enterica serovar typhimurium with emphasis on phage type DT104 based on variable number of tandem repeat loci. J Clin Microbiol. 2003;41(4):1469-79.

http://dx.doi.org/10.1128/JCM.41.4.1469-1479.2003

PMid:12682132 PMCid:PMC153889

19. Lindstedt BA, Vardund T, Aas L, Kapperud G. Multiple-locus variable-number tandem-repeats analysis of Salmonella enterica subsp. enterica serovar Typhimurium using PCR multiplexing and multicolor capillary electrophoresis. J Microbiol Methods. 2004;59(2):163-72. http://dx.doi. org/10.1016/j.mimet.2004.06.014 PMid:15369852

20. Ramisse V, Houssu P, Hernandez E, Denoeud F, Hilaire $V$, Lisanti 0 , et al. Variable number of tandem repeats in Salmonella enterica subsp. enterica for typing purposes. I Clin Microbiol. 2004;42(12):5722-30.

http://dx.doi.org/10.1128/JCM.42.12.5722-5730.2004 PMid:15583305 PMCid:PMC535243

21. Boxrud D, Pederson-Gulrud K, Wotton J, Medus C, Lyszkowicz E, Besser J, et al. Comparison of multiple-locus variable-number tandem repeat analysis, pulsed-field gel electrophoresis, and phage typing for subtype analysis of Salmonella enterica serotype Enteritidis. J Clin Microbiol. 2007;45(2):536-43.

http://dx.doi.org/10.1128/JCM.01595-06 PMid:17151203 PMCid:PMC1829081

22. Clinical and Laboratory Standards Institute (CLSI). Methods for dilution antimicrobial susceptibility tests for bacteria that grow aerobically. Approved standard. 7th ed. M7-A7. 26(2). Wayne: CLSI; Jan 2006. Available from: http://isoforlab.com/ phocadownload/csli/M7-A7.pdf

23. European Commission (EC). 2007/407/EC: Commission decision of 12 June 2007 on a harmonised monitoring of antimicrobia resistance in Salmonella in poultry and pigs. Official Journal L 153. 14 Jun 2007; P. 0026-9. Brussels: EC. Available from: http://eur-lex.europa.eu/LexUriServ/LexUriServ.do?uri=CELEX: 32007D0407:EN:HTML 
24. European Committee on Antimicrobial Susceptibility Testing (EUCAST). Breakpoint tables for interpretation of MICs and zone diameters. Version 3.1 EUCAST; 2013.Available from: www.eucast.org/clinicalbreakpoints/

25. Taormina PJ, Beuchat LR, Slutsker L. Infections associated with eating seed sprouts: an international concern. Emerg Infect Dis. 1999;5(5):626-34.

http://dx.doi.org/10.3201/eido505.990503

PMid:10511518

26. Severi E, Booth L, Johnson S, Cleary P, Rimington M, Saunders D, et al. Large outbreak of Salmonella Enteritidis PT8 in Portsmouth, UK, associated with a restaurant. Epidemiol Infect. 2012:140(10):1748-56 http://dx.doi.org/10.1017/S0950268811002615 PMid:22166322

27. Gobin M, Launders N, Lane C, Kafatos G, Adak B. National outbreak of Salmonella Java phage type 3 b variant 9 infection using parallel case-control and case-case study designs, United Kingdom, July to October 2010. Euro Surveill. 2011;16(47):pii=20023. Available from: http://www. eurosurveillance.org/ViewArticle.aspx?Articleld=20023 PMid:22152706

28. Harker KS, Lane C, De Pinna E, Adak GK. An outbreak of Salmonella Typhimurium DT191a associated with reptile feeder mice. Epidemiol Infect. 2011;139(8):1254-61.

http://dx.doi.org/10.1017/So950268810002281

PMid:20943001

29. McCarthy N, Giesecke J. Case-case comparisons to study causation of common infectious diseases. Int J Epidemiol. 1999;28(4):764-8. http://dx.doi.org/10.1093/ije/28.4.764

30. Lynch MF, Tauxe RV, Hedberg CW. The growing burden of foodborne outbreaks due to contaminated fresh produce: risks and opportunities. Epidemiol Infect. 2009;137(3):307-15. http://dx.doi.org/10.1017/So950268808001969 PMid:19200406

31. Bundesinstitut für Risikobewertung (BfR). [Federal Institute for Risk Assessment]. Stellungnahme: Hohe Keimbelastung in Sprossen und küchenfertigen Salatmischungen. Aktualisierte Stellungnahme Nr. 017/2100 des BfR vom 09. Mai 2011. [Opinion: High microbial load in sprouts and ready-to-eat salad mixtures. Updated BfR opinion no. 017/2100 from 9 May 2011]. Berlin: BfR; May 2011. German. Available from: http://www. bfr.bund.de/cm/349/high_microbial_load_in_sprouts_and_ ready_to_eat_salad_mixtures.pdf

32. European Food Safety Authority (EFSA). Scientific opinion on the risk posed by Shiga toxin-producing Escherichia coli (STEC) and other pathogenic bacteria in seeds and sprouted seeds. EFSA Journal 2011;9(11):2424. Doi:10.2903/j.efsa.2424. Available from: http://www.efsa.europa.eu/en/efsajournal/ pub/2424.htm

33. Foodsafety.gov. Sprouts: what you should know. United States Department of Health and Human Service. Washington: United States Department of Health and Human Services. [Accessed: 12 Nov 2012]. Available from: http://www.foodsafety.gov/ keep/types/fruits/sprouts.html

34. Bundesinstitut für Risikobewertung (BfR). [Federal Institute for Risk Assessment]. Sicher verpflegt. Besonders empfindliche Personengruppen in Gemeinschafteinrichtungen. [Safe food: Especially vulnerable groups in community institutions]. Berlin: BfR; Dec 2011. German. Available from: http://www. bfr.bund.de/cm/350/sicher-verpflegt-besonders-empfindlichepersonengruppen-in-gemeinschaftseinrichtungen.pdf 